\title{
Dynamic faulting on a conjugate fault system detected by near-fault tilt measurements
}

\author{
Eiichi Fukuyama
}

\begin{abstract}
There have been reports of conjugate faults that have ruptured during earthquakes. However, it is still unclear whether or not these conjugate faults ruptured coseismically during earthquakes. In this paper, we investigated near-fault ground tilt motions observed at the IWTH25 station during the 2008 Iwate-Miyagi Nairiku earthquake $\left(M_{w} 6.9\right)$. Since near-fault tilt motion is very sensitive to the fault geometry on which the slip occurs during an earthquake, these data make it possible to distinguish between the main fault rupture and a rupture on the conjugate fault. We examined several fault models that have already been proposed and confirmed that only the models with a conjugated fault could explain the tilt data observed at IWTH25. The results support the existence of simultaneous conjugate faulting during the main rupture. This will contribute to the understanding of earthquake rupture dynamics because the conjugate rupture releases the same shear strain as that released on the main fault, and thus it has been considered quite difficult for both ruptures to accelerate simultaneously.
\end{abstract}

Keywords: Conjugate rupture; 2008 Iwate-Miyagi Nairiku earthquake; Near-fault tilt; Accelerometers

\section{Correspondence/Findings} Introduction

Sometimes an earthquake occurs on a complex fault system such as fault steps, jogs, or branches (Scholz 2002). There have been several field observations on the conjugate faulting. I reviewed several earthquakes as described below and summarized the findings in Figure 1. The earthquakes were categorized into two groups based on the timing of conjugate rupture with respect to the main one. In category 1 earthquakes, the conjugate fault rupture occurred simultaneously with the main rupture, while in category 2 earthquakes, the conjugate fault rupture occurred after the main rupture.

\section{Category 1}

1987 East Chiba earthquake Fukuyama (1991) investigated the rupture process of the 1987 earthquake that occurred off the east coast of Chiba ( $M$ 6.7) based on the relocated aftershock distribution. The rupture was initiated at the deep southern corner where a conjugate fault could be recognized from the relocated aftershock distribution. In this model, the rupture propagated

Correspondence: fuku@bosai.go.jp

National Research Institute for Earth Science and Disaster Prevention, Tsukuba 305-0006, Japan unilaterally along the main fault as well as on the conjugate fault.

1997 Kagoshima earthquake Horikawa (2001) analyzed the May 1997 Kagoshima earthquake ( $M$ 6.0) by inverting strong ground motions based on the fault model constructed by the aftershock distribution (Miyamachi et al. 1999). He concluded that the rupture was initiated close to the junction of two fault segments and propagated bilaterally.

2000 western Tottori earthquake Fukuyama et al. (2003) investigated a detailed aftershock distribution of the 2000 western Tottori earthquake $\left(M_{\mathrm{w}}\right.$ 6.6). They found that there was aftershock activity along the conjugate fault trace within $1 \mathrm{~h}$ after the main shock at the northern end of the coseismic main rupture region close to the main shock hypocenter. This suggests that a possible conjugate rupture occurred simultaneously with the main rupture as expected by the fault model of Iwata and Sekiguchi (2002).

2007 Niigata Chuetsu-Oki earthquake Yukutake et al. (2008) relocated the aftershocks of the 2007 ChuetsuOki earthquake $\left(M_{\mathrm{w}} 6.6\right)$ and found that there was a 


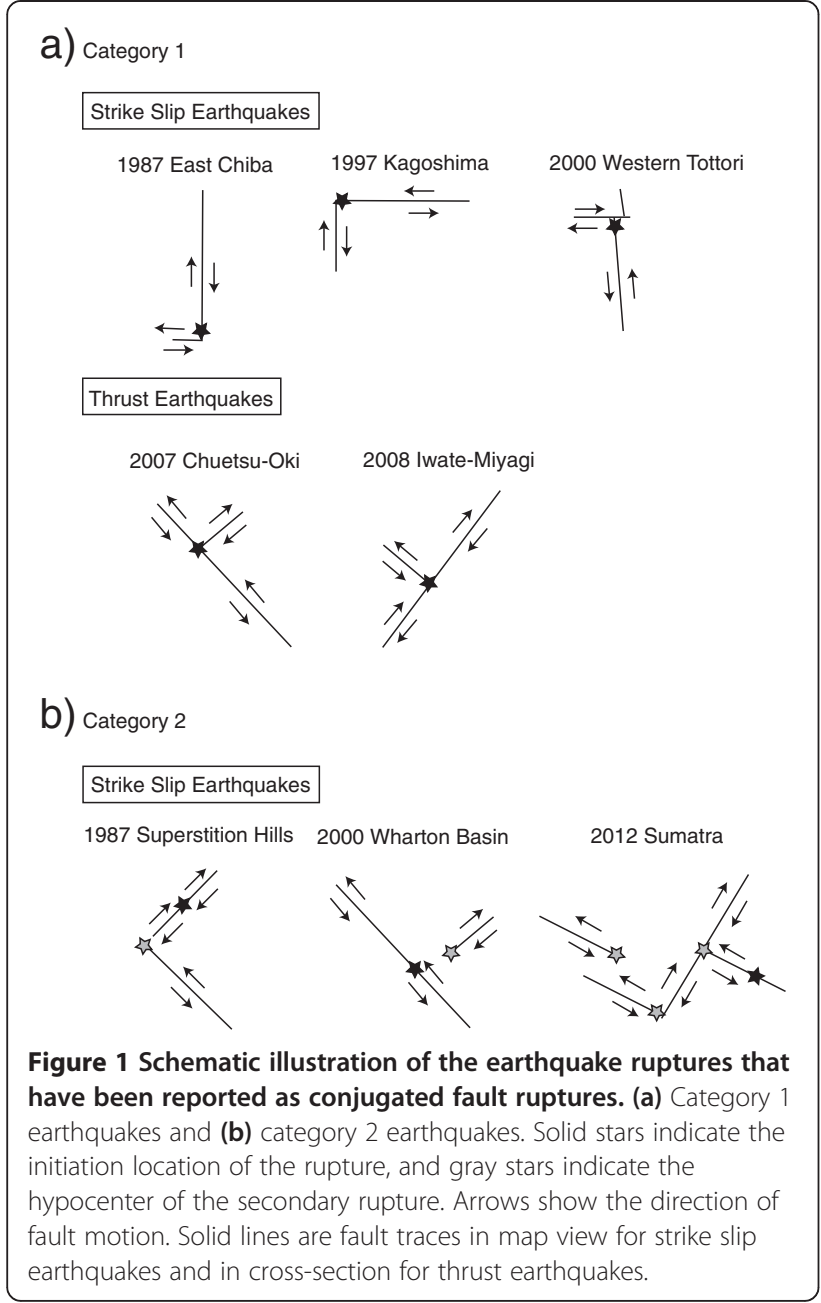

conjugate fault close to the hypocenter region and that the hypocenter was located close to the junction. Aochi and Kato (2010) investigated the possibility of a spontaneous rupture along the conjugated fault using the boundary integral equation method.

\section{Category 21987}

Superstition hills earthquake The Superstition Hills earthquake ( $M$ 6.8) occurred $12 \mathrm{~h}$ after the Elmore Ranch fault earthquake ( $M$ 6.2) (Hudnut et al. 1989; Magistrale et al. 1989; Wald et al. 1990). The Superstition Hills fault is a conjugate of the Elmore Ranch. It should be noted that the Elmore Ranch earthquake was initiated northeast of the fault and the rupture propagated toward the junction. The Superstition Hills earthquake was initiated at the junction and propagated toward the southeast.

2000 Wharton basin earthquake The June 2000 Wharton Basin earthquake $\left(M_{\mathrm{w}} 7.8\right)$ occurred in the region of diffuse deformation between the Indian and
Australian plates, and it is considered as an intraplate earthquake. Robinson et al. (2001) reported, from the analysis of teleseismic waveforms, and relocated aftershock distribution that the Wharton Basin earthquake consisted of two subevents, which were conjugate but they ruptured sequentially. The second rupture initiated around the hypocenter of the first rupture.

2012 Sumatra earthquake The April 2012 Sumatra earthquake $\left(M_{\mathrm{w}}\right.$ 8.6) occurred at the northwestern end of the Wharton Basin. This is an intraplate earthquake similar to the 2000 Wharton earthquake. According to the back projection of teleseismic data from European and Japanese seismic arrays, it consisted of four subevents that were conjugate and were cascaded together; the rupture propagated sequentially (Meng et al. 2012).

Category 2 earthquakes (1987 Superstition Hill, 2000 Wharton Basin, and 2012 Sumatra) ruptured sequentially along the conjugate fault system, while in the category 1 earthquakes (1987 East Chiba, 2000 Western Tottori, and 2007 Niigata Chuetsu-oki), there is the possibility that the rupture propagated simultaneously along both conjugate faults. The aim of this paper is to investigate the category 1 earthquakes in detail.

Based on theoretical modeling of dynamic fault ruptures, several investigations were made on fault steps (e.g., Harris and Day 1993; Kase and Kuge 1998) and fault branches (e.g., Poliakov et al. 2002; Kame et al. 2003). The above observations are consistent with the theoretical investigation of Kase and Kuge (1998) where they found that the conjugate fault could be initiated where the main rupture terminated. $\mathrm{Xu}$ et al. (2015) systematically investigated the physical mechanism of this conjugated faulting using two dimensional (2-D) dynamic rupture simulations. Actually, slip on the two conjugate faults releases the same strain so that it becomes difficult for the rupture to propagate simultaneously on both faults when the main rupture is propagating. The only exception could be at the initiation of the rupture or after the termination of the previous rupture.

It should, however, be noted that all of the above results are based on the relocated aftershock distribution as well as the fault slip distribution estimated by waveform inversions. As can be seen in the fault model database (Mai 2004), waveform inversion results are not unique and may include a certain amount of uncertainty. Thus, there remains the possibility that conjugate faulting did not occur simultaneously during the main rupture. Therefore, we need a solid observation showing that conjugate faulting has occurred during the main rupture.

The Iwate-Miyagi Nairiku earthquake $\left(M_{\mathrm{w}} 6.9, M\right) \mathrm{MA}$ 7.2) occurred on 13 June 2008 at 23:43 (UT). The hypocenter location was estimated to be at a latitude of $39.0269^{\circ} \mathrm{N}$ and a longitude of $140.8779^{\circ} \mathrm{E}$; its depth was 
$6.5 \mathrm{~km}$ (Sekine et al. 2008). This was one of the largest intraplate earthquakes with reverse faulting that had occurred at a shallow depth inland in northeast Japan. According to the F-net moment tensor estimated by regional broadband seismograms, the estimated fault strike, dip, and rake angles were $\mathrm{N} 209^{\circ} \mathrm{E}, 51^{\circ}$, and $104^{\circ}$, respectively, and the seismic moment was estimated to be $2.72 \times 10^{19} \mathrm{Nm}$ (NIED 2008a). Based on the aftershock distribution estimated by the Hi-net microseismic network, the fault length and width were roughly 30 and $10 \mathrm{~km}$, respectively (NIED 2008b).

Before the earthquake, no active fault traces had been recognized in the source region. However, immediately after the earthquake, several fault surface breaks were observed (e.g., Ishiyama et al. 2008; Maruyama et al. 2009), suggesting a west-northwest dipping reverse fault with north-northeast strike.

In this paper, in order to investigate the conjugate faulting during the main rupture, we analyzed the near-fault accelerograms to estimate the coseismic tilt motion in addition to the tiltmeter collocated as well as Global Positioning System (GPS) data. Through this analysis, we constrained the fault slip model of the 2008 Iwate-Miyagi Nairiku earthquake and clarified whether a conjugated fault slip occurred during the main rupture based on the near-fault tilt data.

\section{Tilt observations}

The IWTH025 station, which is a KiK-net and Hi-net station (latitude $39.00923^{\circ} \mathrm{N}$, longitude $140.86363^{\circ} \mathrm{E}$, height $386 \mathrm{~m}$; the location was confirmed by a field survey), which is called Ichinoseki-Nishi, and it is located very close to the epicenter of the 2008 Iwate-Miyagi Nairiku earthquake $(2.3 \mathrm{~km}$ south-southwest of the epicenter, Figure 2a). At this station, a three-component accelerometer was installed on the surface, and a three-component accelerometer, a three-component velocity seismometer, and a two-component tiltmeter were installed at the bottom of a 260-m-deep borehole (Figure 2c). The corresponding records should provide us with important information on the source process of this earthquake. Since the tiltmeter was designed to measure tiny tilt changes such as from earth tides (approximately $10^{-7}$ radians), the observation range was not sufficient to measure such a huge ground tilt near the fault. Thus, the signal was saturated immediately after the earthquake occurred, and the tiltmeter recorded only the static tilt change after the seismic radiation passed away (see Figure 3).

\section{Tilt measured by accelerograms}

We first computed ground displacements on the surface as well as at the bottom of the borehole of the IWTH25 station by numerically integrating the accelerograms two times in the time domain. In this integration procedure, we only removed the initial offset of acceleration in the original records and we kept the other offsets in the following processes. It should be noted that we did not apply any baseline corrections to the accelerograms except for the initial offset for the following reason.

It is well known that strong motion accelerograms sometimes include baseline shifts caused by local tilts. When an accelerogram tilts, its axes deviate from the gravity axis, which causes additional acceleration. Several techniques for baseline correction have been proposed (e.g., Iwan et al. 1985; Boore 2001; Graizer 2006; Kinoshita 2008). However, as pointed out by Boore et al. (2002), translation motion and rotation motion observed by pendulum-type seismometers cannot intrinsically be separated. Thus, it is theoretically impossible to extract the rotation component from an accelerogram. Therefore, in the present analysis, we did not correct the baselines to obtain the displacements. We judged that a baseline shift occurred (i.e., rotational motion occurred) only when the displacements behaved as $\mathrm{t}^{2}$-type displacements.

As can be seen in Figure 4, ground displacements behaved in almost the same way for both locations. In particular, they were almost identical in terms of their UD (up-down) and NS (north-south) components until $5 \mathrm{~s}$. Careful observation shows that in the EW (east-west) component, a significant difference (approximately $0.2 \mathrm{~m}$ ) between the two displacements occurred between 3 and $8 \mathrm{~s}$ (Figure 4). Since the ground motion displacements of UD and NS moved similarly for both surface and borehole data until $5 \mathrm{~s}$, and no $\mathrm{t}^{2}$-type behavior was observed in the EW component during this time window, the difference in the EW component should be considered as a well-recorded signal of ground motion reflecting a large-scale deformation (at least larger than $260 \mathrm{~m}$ in scale). This motion can be interpreted as a rotation along the horizontal axis oriented in the NS direction, i.e., EW tilt motion. Since the distance between the two accelerograms was $260 \mathrm{~m}$, the tilt angle change was calculated to be $0.8 \times 10^{-3}$ radians (Table 1 ), which is five orders of magnitude larger than that of a typical tidal change observed by conventional tiltmeters. Hereafter, we call this tilt motion DIF tilt. It should be noted that this tilt change occurred during the coseismic deformation, i.e., during the increase in displacements.

Regarding the NS component, the surface displacement started to behave as $\mathrm{t}^{2}$-type after $5 \mathrm{~s}$ (Figure 4) so that in this time window the NS displacement at the surface might include surface tilt around the sensor. We could see similar features in the UD and EW components. Thus, we could not estimate the NS tilt motion correctly and we were unable to determine whether it was positive or negative.

The error in the tilt estimates depends on how precisely the displacements were estimated at both locations, and a 

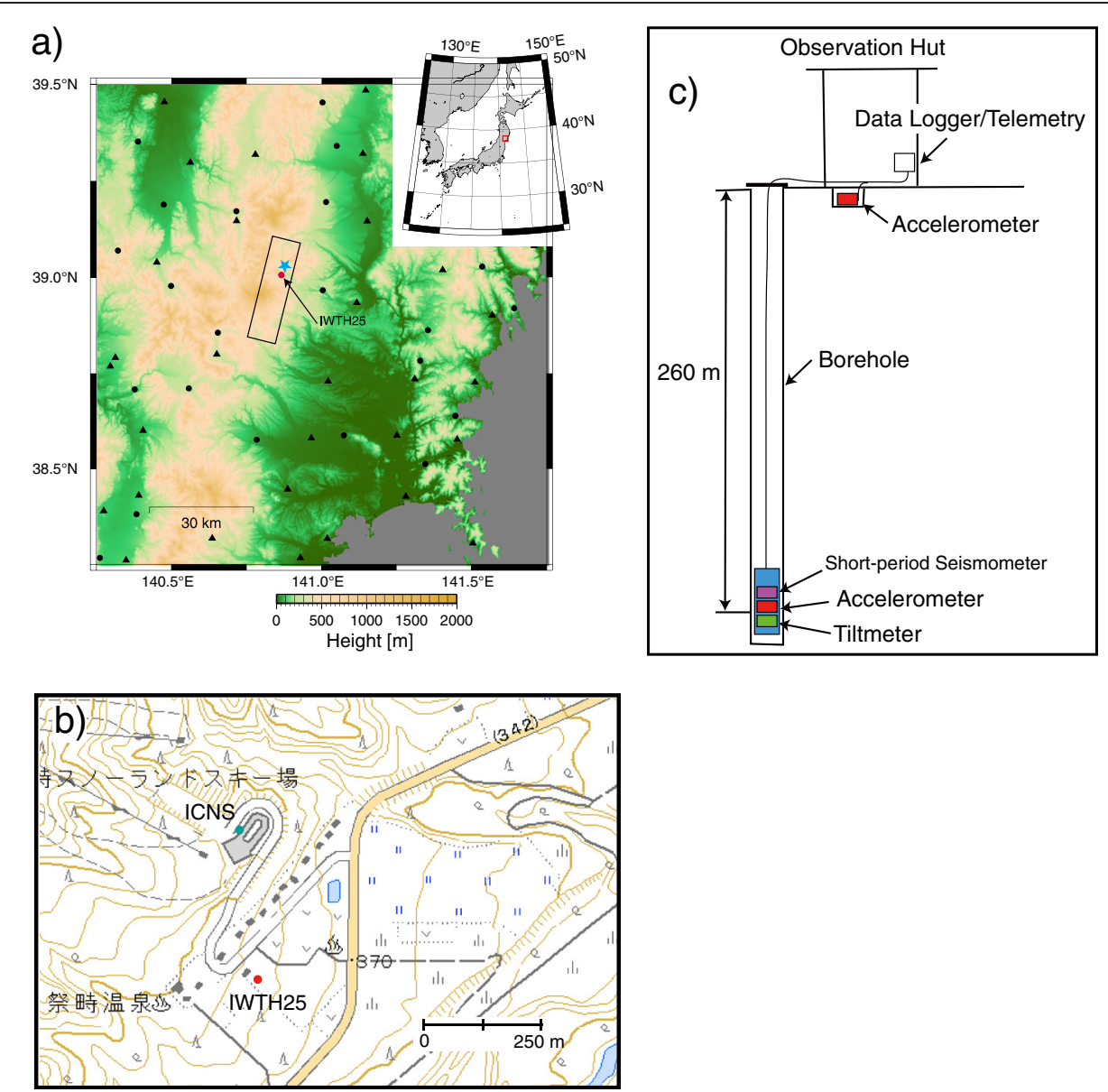

Figure 2 Location of the IWTH25 station and its observation system. (a) Location of the IWTH25 station (red circle) plotted with other K-NET (solid triangles) and KiK-net stations (solid circles). The blue star indicates the epicenter location of the 2008 Iwate-Miyagi Nairiku earthquake. The rectangular region shows the fault area of the 2008 earthquake. The red open rectangle in the upper right inset stands for the area plotted. (b) Close-up view of the location of IWTH25 plotted with the GPS station ICNS. The map image data is from the Geological Survey of Japan through http:/cyberjapan.jp. Brown contours indicate the heights at an interval of $20 \mathrm{~m}$. (c) Schematic illustration of the IWTH25 station. Beneath the observation hut, a three-component accelerometer was installed, and it was isolated from the basement of the hut. In front of the hut, a 260-m-deep borehole was dug. At the bottom of the borehole, a sensor capsule was installed that included a three-component short-period velocity seismometer, a three-component accelerometer, and a two-component tiltmeter.

typical uncertainty in displacement is on the order of $3 \mathrm{~cm}$. Therefore, the uncertainty in tilt motion reached $1 \times 10^{-4}$ radians in this case.

\section{Static tilt measured by other instruments}

Some other observations were made of the static tilt change at and around the IWTH25 station. Static tilt change represents the tilt change measured by the difference between the tilt before and after the earthquake, thus it might include post-seismic deformation in addition to the coseismic one. A pendulum-type tiltmeter was installed at the bottom of the borehole in the same capsule as the borehole accelerometer. The static tilt change was observed to be $0.23 \times 10^{-3}$ radians down to the east and $0.14 \times 10^{-3}$ radians down to the north (Figure 3a, Table 1 ). This is more or less consistent with the DIF tilt observed by the accelerometers. Although the magnitude of the EW tilt change measured by the tiltmeter was smaller, the tilt direction was consistent with those of the accelerograms taking into account the uncertainty in the NS component.

From the accelerogram on the surface, we could estimate the surface tilt by measuring the static offset appearing in the surface accelerogram, which was $2.2 \times 10^{-3}$ radians down to the east (Figure $3 \mathrm{~b}$, Table 1 ). We call this tilt SUF tilt to avoid potential confusion with DIF tilt. The SUF tilt change was larger than the DIF tilt change, but the tilt direction was again consistent with the DIF tilt. In the borehole accelerogram, the static offsets were not consistent among the three components, suggesting that these offsets were not caused only by tilt motion. Accordingly, we did not use the offset of the borehole accelerogram for the tilt estimation. 

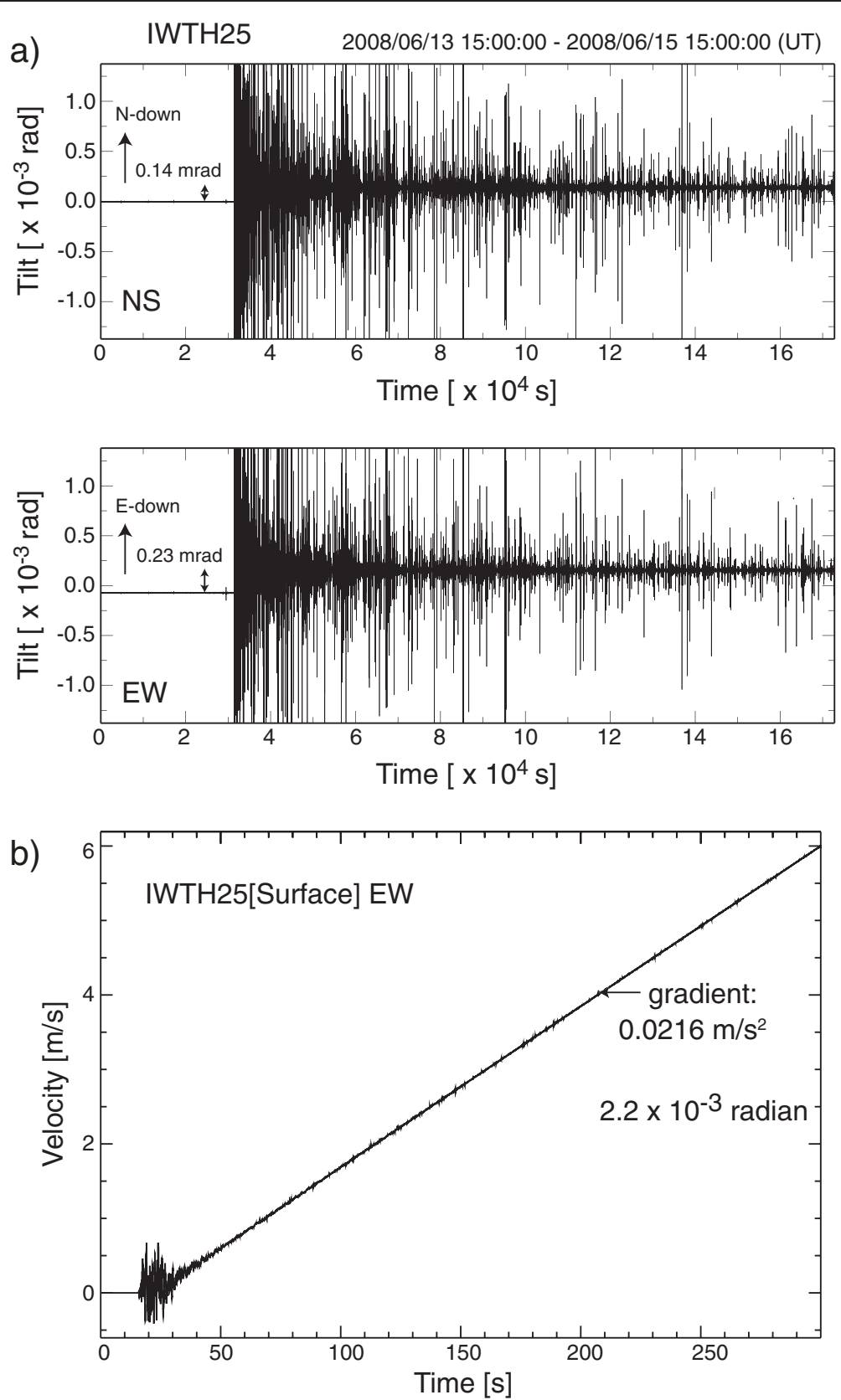

Figure 3 Tilt data at the IWTH25 station. (a) Tilt change data observed by the tiltmeter installed at the bottom of the borehole at the IWTH25 station. The full scale of the recording system was about $\pm 1.6 \times 10^{-3}$ radians (the same as the full scale plotted). The static tilt changes were observed after the large amplitude oscillation ended. (b) Velocity seismogram of the surface accelerometer at the IWTH25 station. The initial offset in the original accelerogram was removed before numerical integration. The gradient of the velocity observed after the main waveforms corresponds to the acceleration step caused by the tilt change.

In addition, we could roughly estimate the tilt change using the GPS displacement at the station named ICNS $\left(39.01206^{\circ} \mathrm{N}, 140.86314^{\circ} \mathrm{E}, 468.5 \mathrm{~m}\right.$, Figure $\left.2 \mathrm{~b}\right)$ with respect to the displacement at IWTH25. The coseismic displacements at ICNS were estimated to be $0.439 \mathrm{~m}$ to the east, $0.339 \mathrm{~m}$ to the north, and $1.557 \mathrm{~m}$ upward (Ohta et al. 2008, Table 1). Since the ICNS station is located about $320 \mathrm{~m} \mathrm{~N} 6.5^{\circ} \mathrm{W}$ from IWTH25, and it is $83 \mathrm{~m}$ higher than that of IWTH25 (Figure 2b), a tilt motion of $3 \times 10^{-3}$ radians down to the east can be estimated (Table 1). This is again consistent with other observations.

\section{Interpretation of tilt data}

The tilt estimated above should be quite useful for interpreting the dynamic faulting of this earthquake. Several kinematic fault models have been proposed for this 


\section{a)}

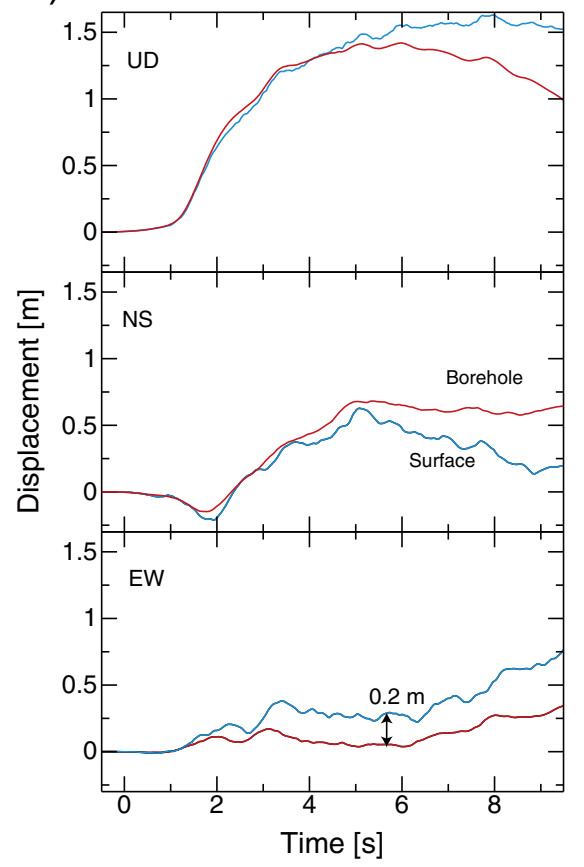

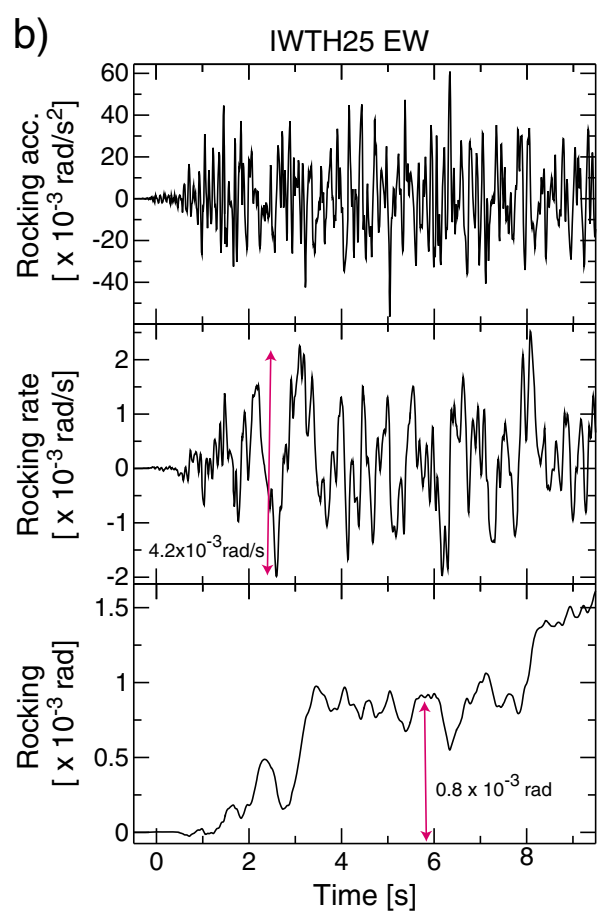

Figure 4 Displacement and tilt waveforms at IWTH25. (a) Displacement waveforms on the surface (red) and at the bottom of the borehole (blue) of the IWTH25 station. The origin on the time axis corresponds to the first arrival time of the signal. (b) Temporal variation of the tilt (bottom), its velocity (middle), and its acceleration (top). Tilt motion was computed as the difference between the surface data and borehole data divided by the distance $(260 \mathrm{~m})$.

earthquake. Ohta et al. (2008) constructed a fault model consisting of two planar faults by inverting GPS data around the source region. Takada et al. (2009) estimated a fault model to fit the Interferometric Synthetic Aperture Radar (InSAR) data. Takada's model consists of five planar reverse faults, one of which has a conjugate dip. Abe et al. (2013) updated Takada's model by assuming two nonplanar fault segments. Asano and Iwata (2008), Suzuki et al. (2010), and Cultrera et al. (2013) estimated the kinematic fault motion using strong motion seismograms. Hikima et al. (2008) used strong motion and geodetic data. Yokota et al. (2009) used 1-Hz GPS data. Asano and Iwata (2008), Hikima et al. (2008), Yokota et al. (2009), Suzuki et al. (2010), and Cultrera et al. (2013) assumed one planar fault

Table 1 Observed and predicted displacements and tilts at IWTH25 and ICNS

\begin{tabular}{|c|c|c|c|c|c|}
\hline Data/Model & Disp. East [m] & Disp. North [m] & Disp. up [m] & Tilt E-down $\left[\times 10^{-3}\right.$ radian] & Tilt N-down $\left[\times 10^{-3}\right.$ radian $]$ \\
\hline ICNS GPS $^{1}$ & 0.439 & 0.339 & 1.577 & - & - \\
\hline IWTH25acc_S $S^{2}$ & 0.3 & 0.65 & 1.5 & 2.16 & -0.73 \\
\hline IWTH25acc_B ${ }^{3}$ & 0.1 & 0.65 & 1.5 & - & - \\
\hline IWTH25tilt ${ }^{4}$ & - & - & - & 0.23 & 0.14 \\
\hline IWTH25_diff' & - & - & - & 0.8 & $> \pm 0.1$ \\
\hline IWTH25-ICNS ${ }^{6}$ & - & - & - & 3.2 & -3.9 \\
\hline Ohta et al. (2008) & 0.235 & -0.179 & 0.341 & -0.122 & 0.010 \\
\hline Takada et al. (2009) ${ }^{8}$ & 0.367 & -0.517 & 0.580 & -0.054 & -0.056 \\
\hline Suzuki et al. (2010) ${ }^{9}$ & 0.321 & 0.334 & 0.892 & -0.097 & 0.110 \\
\hline Suzuki + conj. fault ${ }^{10}$ & 0.258 & 0.599 & 1.465 & 0.108 & 0.141 \\
\hline
\end{tabular}

${ }^{1}$ GPS displacement at ICNS station taken from (Ohta et al. 2008). ${ }^{2}$ Displacement and tilt (SUF tilt) measured by the surface accelerogram at IWTH25. ${ }^{3}$ Displacement measured by the borehole accelerogram at IWTH25. ${ }^{4}$ Tilt measured by the tiltmeter at IWTH25. ${ }^{5}$ Tilt measured by the spatial derivative of surface and borehole displacements at IWTH25 (DIF tilt). ${ }^{6}$ Tilt measured by the spatial derivative between ICNS and IWTH 25 (borehole). ${ }^{7-9}$ Predicted displacements and tilts at IWTH 25 by the fault models of Ohta et al. (2008), Takada et al. (2009), and Suzuki et al. (2010), respectively. ${ }^{10}$ Predicted displacements and tilts at IWTH25 by the fault model of Suzuki et al. (2010) with fault 3 (conjugate fault) of Takada et al. (2009). 
divided by approximately $2 \times 2 \mathrm{~km}^{2}$ subfaults, and the strike- and dip-slip developments were estimated at each subfault.

Here, we compute the ground deformation at the IWTH25 station using the models by Ohta et al. (2008), Takada et al. (2009), and Suzuki et al. (2010). Ground displacements and ground tilts were computed using the crustal deformation code from Okada (1992). The results are summarized in Table 1.

As shown in Ohta et al. (2008), the model by Ohta et al. could not fit the GPS data at ICNS which is close to the IWTH25 station. Thus, apparently, this model could not explain the deformation at IWTH25 as shown in Table 1. This is because they used only two planar rectangular faults, on each of which uniform slip was assumed. Therefore, the fault model estimated using GPS data was not suitable for the present purpose.

Suzuki et al. (2010) used 180 subfaults (each with $2 \times 2 \mathrm{~km}^{2}$ areas) with seven time windows (each has a 0.8 -s duration with an interval of $0.4 \mathrm{~s}$ ) and estimated strike- and dip-slips at each spatiotemporal window. Thus, their model includes spatial variation of slip on the fault as well as rake angle variation in spite of a planar single fault assumption. As shown in Figure 5 and Table 1, in their model, the ground deformation direction could be explained, where the existence of the shallow asperity controls the ground deformation.
However, their model could not explain the tilt direction at IWTH25.

Takada et al. (2009) inverted the InSAR data to estimate the orientation of five planar faults and their slips. In order to explain the spatial extent of the large displacement area on the surface, they introduced a conjugate fault (fault 3 in Takada et al. 2009) at the western boundary of the aftershock region. In their model, since the IWTH25 station is located at the edge of rectangular faults, near-field ground deformation cannot be modeled well there (Figure 6 and Table 1). In addition, it is not clear whether the estimated slip on the conjugate fault occurred coseismically during the earthquake or after the earthquake as a post-seismic deformation because the acquisition of satellite imagery data for InSAR analysis was not continuous. However, it is worth considering the conjugate fault because the InSAR data include information on the spatial extent of the slip that was not constrained by other observations.

Therefore, we think that both the heterogeneous slip distribution on the main west-dipping fault and some contribution on the east-dipping conjugate fault are required to explain the ground deformation and ground tilt at the IWTH25 station. Thus, we computed the ground deformation with the Suzuki et al. (2010) slip model and the conjugate fault (fault 3 of Takada et al. 2009) (Figure 7 and Table 1). The obtained results fit
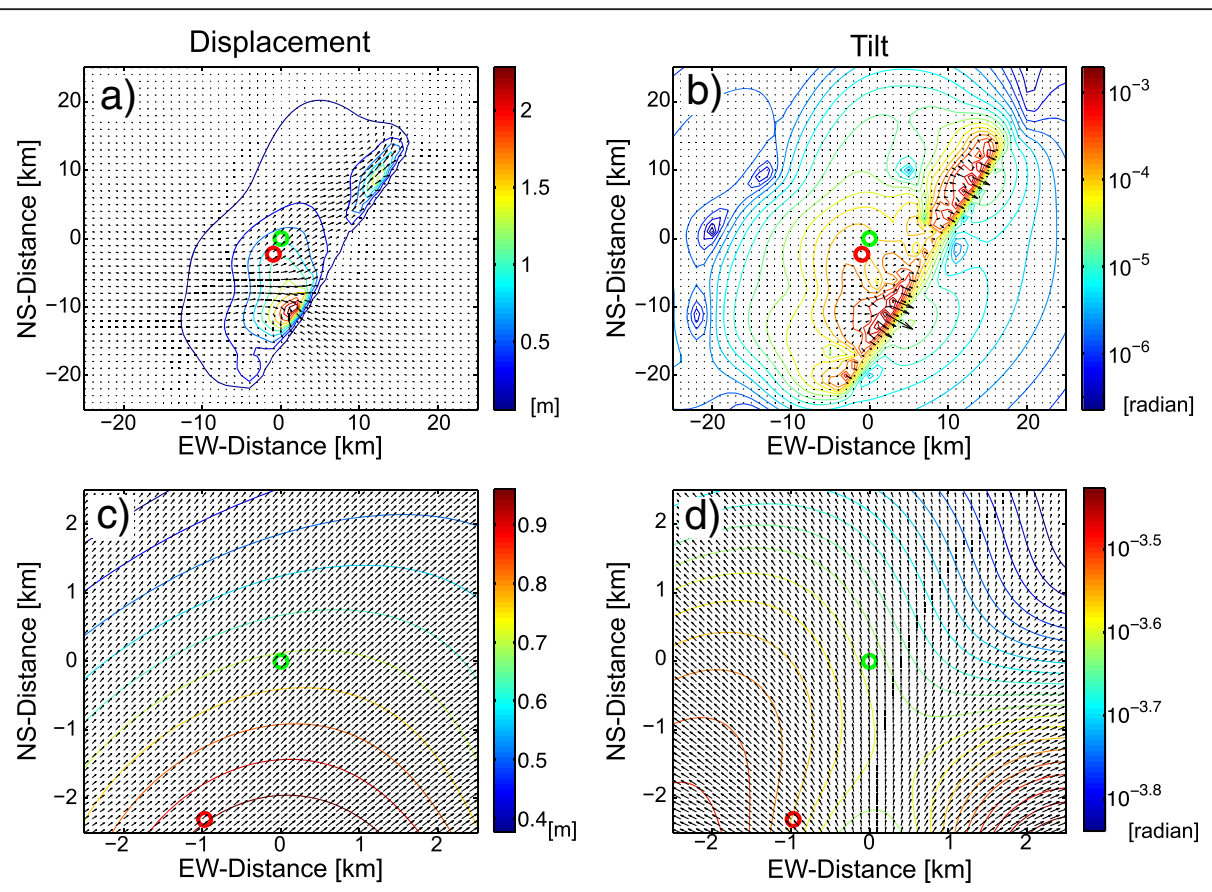

Figure 5 Ground deformation and ground tilt computed using the Takada et al. (2009) model. (a) Ground displacements are shown. Arrows represent horizontal displacements and contours indicate vertical displacements. (b) Ground tilt distribution. Arrows show the tilt direction (dipping direction) and contours show the magnitudes of tilt. (c) Magnified version of (a). (d) Magnified version of (b). Green and red circles show the locations of the epicenter and the IWTH25 station, respectively. 

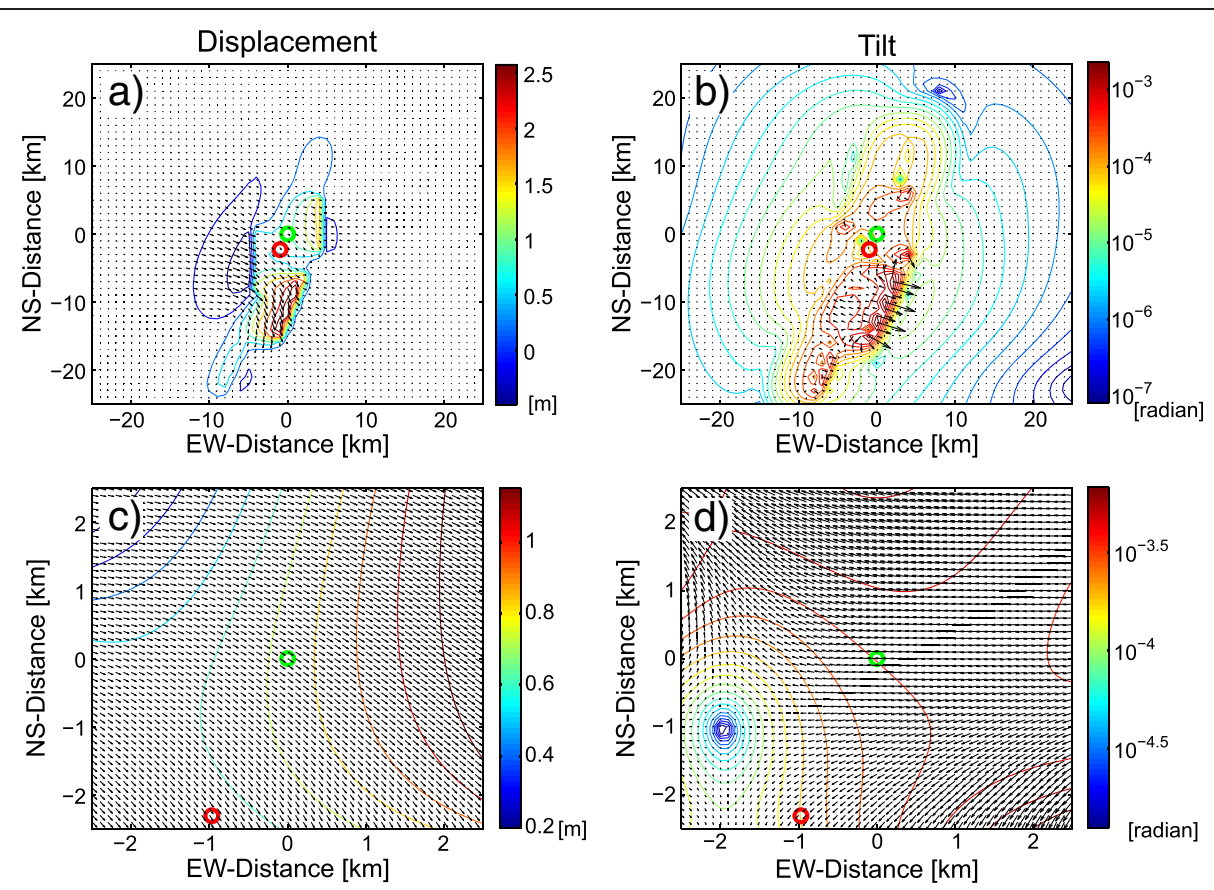

Figure 6 Ground deformation and ground tilt computed using the Suzuki et al. (2010) model. (a) Ground displacements, (b) ground tilt distribution, (c) magnified version of (a), and (d) Magnified version of (b). Legends are the same as in Figure 5.
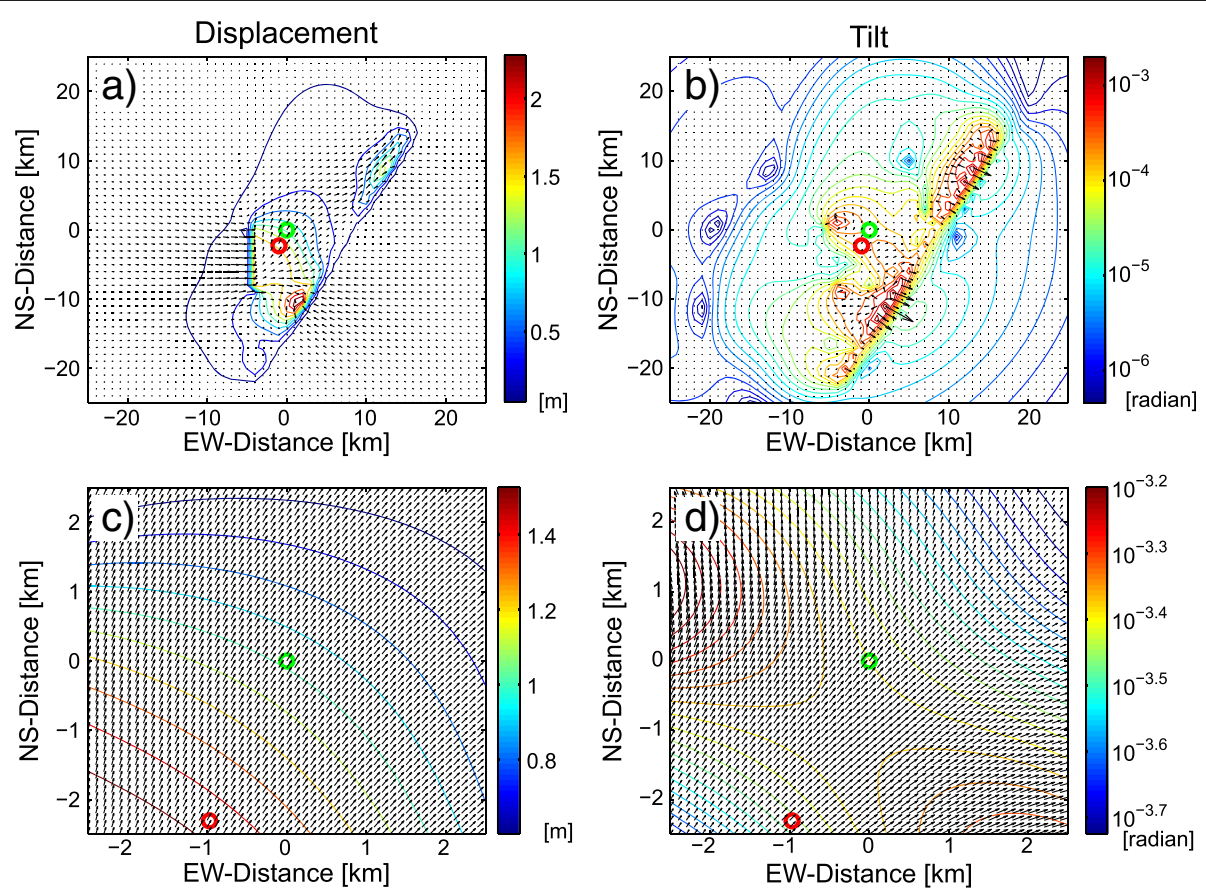

Figure 7 Ground deformation and ground tilt computed using the Suzuki's model with Takada's conjugate fault. Main fault slip distribution is taken from Suzuki et al. (2010) and the conjugate fault is from fault 3 of Takada et al. (2009). (a) Ground displacements, (b) ground tilt distribution, (c) magnified version of (a), and (d) Magnified version of (b). Legends are the same as in Figure 5. 
remarkably well with the observations at IWTH25. Thus, we concluded that a conjugate fault slip is required to explain the displacement and tilt motion at IWTH25.

An interesting consequence of this result is that the slip on the conjugate fault occurred simultaneously during the dynamic rupture of this earthquake on the main fault because the tilt change at IWTH25 occurred coseismically during the earthquake rupture as indicated above. If both the west-dipping main fault and the east-dipping conjugate fault slipped simultaneously during the earthquake, the initiation mechanism for the conjugate fault rupture might be of interest. It should be pointed out that the conjugate fault and the branched fault had opposite slip directions at the junction. In the future, it would be interesting to investigate the rupture dynamics for the simultaneous rupture of conjugate faults in the future.

\section{Conclusion}

At the IWTH25 station, near-field tilt motion was observed by two sets of accelerometers vertically collocated on the surface and at the bottom of a 260-m-deep borehole during the 2008 Iwate-Miyagi Nairiku earthquake. The amount of tilt was estimated to be $0.8 \times 10^{-3}$ radians down to the east. To explain this tilt motion based on pre-existing fault models, we concluded that a slip along the conjugate fault coseismically occurred during the earthquake. This represents an important direct observation of a conjugated fault rupture in the field.

\section{Competing interests}

The author declares that he has no competing interests.

\begin{abstract}
Acknowledgements
S. Aoi provided with the detailed site condition data at IWTH25. H. Hirose provided the tilt data at IWTH25, which was originally stored in the Hi-net data center at the National Research Institute for Disaster Prevention (NIED). W. Suzuki provided his slip model. Accelerograms at IWTH25 were provided by the KiK-net data center at NIED. Discussions with Y. Takada, S. Hok, S. Aoi, W. Suzuki, and N. Pulido were quite valuable. Comments by two anonymous reviewers were also very helpful. I appreciate A. Nishizawa for her editorial work on this manuscript. This work was supported by a NIED research project titled "Development for Crustal Activity Monitoring and Forecasting."
\end{abstract}

Received: 31 October 2014 Accepted: 19 February 2015

Published online: 10 March 2015

\section{References}

Abe T, Furuya M, Takada Y (2013) Nonplanar fault source modeling of the 2008 Mw6.9 Iwate-Miyagi inland earthquake in northeast Japan. Bull Seismol Soc Am 103(1):507-518, doi:10.1785/0120120133

Aochi H, Kato A (2010) Dynamic rupture of crosscutting faults: a possible rupture process for the 2007 Mw 6.6 Niigata-ken Chuetsu-oki earthquake. J Geophys Res 115, B05310, doi:10.1029/2009JB006556

Asano K, Iwata T (2008) Kinematic source rupture process of the 2008 Iwate-Miyagi Nairiku earthquake, a Mw6.9 thrust earthquake in northeast Japan, using strong motion data. Eos Trans AGU Fall Meet Suppl Abstract 89(53):S23B-S1890B

Boore DM (2001) Effect of baseline corrections on displacements and response spectra for several recordings of the 1999 Chi-Chi, Taiwan, earthquake. Bull Seismol Soc Am 91:1199-1211
Boore DM, Stephens CD, Joyner WB (2002) Comments on baseline correction of digital strong-motion data: examples from the 1999 Hector Mine, California, earthquake. Bull Seismol Soc Am 92:1543-1560

Cultrera G, Ameri G, Saraò A, Cillera A, Emolo A (2013) Ground-motion simulations within ShakeMap methodology: application to the 2008 Iwate-Miyagi Nairiku (Japan) and 1980 Irpinia (Italy) earthquakes. Geophys J Int 193:220-237, doi:10.1093/gji/ggs074

Fukuyama E (1991) Inversion for the rupture details of the 1987 east Chiba earthquake, Japan, using a fault model based on the distribution of relocated aftershocks. J Geophys Res 96(B5):8205-8217

Fukuyama E, Ellsworth WL, Waldhauser F, Kubo A (2003) Detailed fault structure of the 2000 western Tottori, Japan, earthquake sequence. Bull Seismol Soc Am 93(4):1468-1478

Graizer VM (2006) Tilts in strong motion. Bull Seismol Soc Am 96:2090-2102

Harris RA, Day SM (1993) Dynamics of fault interaction: parallel strike-slip faults. J Geophys Res 98(B3):4461-4472

Hikima K, Miyazaki S, Koketsu K (2008) Rupture process of the 2008 Iwate-Miyagi Nairiku earthquake (Mj7.2), Japan, inferred from strong motion and geodetic data. Eos Trans AGU Fall Meet Suppl Abstract 89(53):S51D-S1789D

Horikawa H (2001) Earthquake doublet in Kagoshima, Japan: rupture of asperities in as stress shadow. Bull Seismol Soc Am 91(1):112-127

Hudnut KW, Seeber L, Pacheco J (1989) Cross-fault triggering in the November 1987 superstition hills earthquake sequence, southern California. Geophys Res Lett 16(2):199-202

Ishiyama T, Imaizumi T, Koshiya S, Sugito N, Tsutsumi H, Hirouchi D, Marushima N (2008) Surface earthquake fault scarp appearing at Hanokidachio, Ichinoseki-city, during the 2008 Iwate-Miyagi Nairiku earthquake. Active Fault Res 29:iv, in Japanese

Iwan WD, Moser MA, Peng CY (1985) Some observations on strong-motion earthquake measurement using a digital accelerograph. Bull Seismol Soc Am 75:1225-1246

Iwata T, Sekiguchi H (2002) Source process and near-source ground motion during the 2000Tottori-ken Seibu earthquake. In: Project Report of the MEXT Grant-in-aid for Scientific Research (B) No. 11694134 "Assessment of Seismic Local-Site Effect at Plural Test Sites". pp 231-241

Kame N, Rice JR, Dmowska R (2003) Effects of prestress state and rupture velocity on dynamic fault branching. J Geophys Res 108(B5):2265, doi:10.1029/ 2002JB002189

Kase Y, Kuge K (1998) Numerical simulation of spontaneous rupture processes on two non-coplanar faults: the effect of geometry on fault interaction. Geophys J Int 135:911-922

Kinoshita S (2008) Tilt measurement using broadband velocity seismograms. Bull Seismol Soc Am 98:1887-1897

Magistrale H, Jones L, Kanamori H (1989) The superstition hills, California earthquake of 24 November 1987. Bull Seismol Soc Am 79(2):239-251

Mai PM (2004) SRCMOD: a database of finite-source rupture models. http:// equake-rc.info/SRCMOD/ Accessed 14 Oct 2014

Maruyama T, Toda S, Yoshimi M, Omata M (2009) Application of airborne LiDAR to mapping surface ruptures and active faults: an example from the 2008 Iwate-Miyagi Nairiku, Japan, earthquake (Mw6.9). Active Fault Res 30:1-12 (in Japanese with English abstract)

Meng L, Ampuero JP, Stock J, Duputel Z, Luo Y, Tsai VC (2012) Earthquake in a Maze: Compressional rupture branching during the 2012 Mw 8.6 Sumatra earthquake. Sci 337:724-726

Miyamachi H, Iwakiri K, Yakiwara H, Goto K, Kakuta T (1999) Fine structure of aftershock distribution of the 1997 northwestern Kagoshima earthquake with a three-dimensional velocity model. Earth Planets Space 51:233-246

NIED (2008a) http://www.fnet.bosai.go.jp/event/tdmt.php? ID $=20080613234200 \& L A N G=e n$. Accessed on 7 Jan 2015

NIED (2008b) http://www.hinet.bosai.go.jp/topics/iwate-miyagi080614/?LANG=en. Accessed on 7 Jan 2015 (in Japanese)

Ohta Y, Ohzono M, Miura S, linuma T, Tachibana K, Takatsuka K, Miyao K, Sato T, Umino N (2008) Coseismic fault model of the 2008 Iwate-Miyagi Nairiku earthquake deduced by a dense GPS network. Earth Planets Space 60:1197-1201

Okada Y (1992) Internal deformation due to shear and tensile faults in a half-space. Bull Seismol Soc Am 82(2):1018-1040

Poliakov AN, Dmowska R, Rice JR (2002) Dynamic shear rupture interactions with fault bends and off-axis secondary faulting. J Geophys Res 107(B11):2295, doi:10.1029/2001JB000572

Robinson DP, Henry C, Das S, Woodhouse JH (2001) Simultaneous rupture along two conjugate planes of the Wharton Basin earthquake. Sci 292:1145-1148 
Scholz CH (2002) The mechanics of earthquake faulting. Cambridge University Press, Cambridge, 496 pp. ISBN 0521655404

Sekine S, Shiomi K, Takeda T, Asano Y, Obara K, (2008) Complex seismic activity within the source region of 2008 Iwate-Miyagi Nairiku earthquake on the basis of double-difference analysis. Paper presented at The 7th general assembly of Asian Seismological Commission and the 2008 fall meeting of Seismological Society of Japan, Tsukuba International Conference Hall, Tsukuba, 24-27 November 2008, X1-017 (in Japanese)

Suzuki W, Aoi S, Sekiguchi H (2010) Rupture process of the 2008 Iwate-Miyagi Nairiku, Japan, earthquake derived from near-source strong-motion records. Bull Seismol Soc Am 100(1):256-266, doi:10.1785/0120090043

Takada Y, Kobayashi T, Furuya M, Murakami M (2009) Coseismic displacement due to the 2008 Iwate-Miyagi Nairiku earthquake detected by ALOS/PALSAR: preliminary results. Earth Planets Space 61:e9-e12

Wald DJ, Helmberger DV, Hartzell SH (1990) Rupture process of the 1987 superstition hills earthquake from the inversion of strong motion data. Bull Seismol Soc Am 80(5):1079-1098

Xu S, Fukuyama E, Ben-Zion Y, Ampuero JP (2015) Dynamic rupture activation of backthrust fault branch. Tectonophysics 644-645:161-183, doi:10.1016/j. tecto.2015.01.011

Yokota Y, Koketsu K, Hikima K, Miyazaki S (2009) Ability of 1-Hz GPS data to infer the source process of a medium-sized earthquake: the case of the 2008 Iwate-Miyagi Nairiku, Japan, earthquake. Geophys Res Lett 36:L12301, doi:10.1029/2009GL037799

Yukutake Y, Takeda T, Obara K (2008) Well-resolved hypocenter distribution using the double-difference relocation method in the region of the 2007 Chuetsu-oki earthquake. Earth Planets Space 60:1105-1109

\section{Submit your manuscript to a SpringerOpen ${ }^{\circ}$ journal and benefit from:}

- Convenient online submission

- Rigorous peer review

- Immediate publication on acceptance

- Open access: articles freely available online

- High visibility within the field

- Retaining the copyright to your article 